\title{
METHANE FLUXES FROM AND TO A DRAINED GRASSLAND ON A PEAT SOIL: MODELLING METHANE PRODUCTION
}

\author{
R. Segers and P.A. Leffelaar
}

Department of Theoretical Production Ecology, Wageningen Agricultural University, PO Box 430, 6700 AK Wageningen, The Netherlands.

Email: REINOUD.SEGERS@STAFF@TPE.WAU.NL

\begin{abstract}
A process based model for methane fluxes from or to a drained grassland on a peat soil was set up. The methane production submodel was developed with the aid of experimentally determined time series of methane and acetate in anaerobically incubated soil samples. This submodel was calibrated by the first part of the time series and validated by the second part. The modelling activity indicated that, for explaining field fluxes, knowledge about the decay of methanogenic bacteria during aerobiosis is needed, as well as knowledge about the role of alternative electron acceptors and about anaerobiosis dynamics.
\end{abstract}

\section{INTRODUCTION}

At a drained grassland on a peat soil in Zegveld, The Netherlands, methane fluxes have been monitored by Van Dasselaar and Oenema (1994) during one year. They found that emission did not exceed $0.3 \mathrm{mg} \mathrm{m}^{-2} \mathrm{~d}^{-1}$. In this paper a process based model to describe methane fluxes at the studied site is presented. Emphasis will be on the first results of the methane production submodel. With the model we intend to investigate, whether low emission, even during wet periods, can be explained by the duration of the anaerobic periods, which could be too short to allow the methanogenic consortium in the top soil to grow sufficiently to produce significant amounts of methane. The framework of this study and the studied site are described elsewhere in this volume (Segers and Van Dasselaar, 1994).

\section{MODEL SET UP}

The model comprises four submodels: water dynamics, gas transport, methane production and methane consumption (Figure 1). Water dynamics is mimicked by Richards' Equation using the Van Genuchten Parameters (Van Genuchten, 1980) from the Staring Series (Wösten et al., 1994) for the soil water retention and conductivity curves. The water model will be validated with measured water contents. From the water model gas filled porosities as a function 
of depth will be derived and used as input for the gas transport model. Initially we will assume that each soil layer is homogeneous and that gas transport does occur only in the soil gas phase by diffusion. Analysis of first results could lead to the study of soil structure and the inclusion of gas transport in (nearly) water saturated aggregates and soil respiration to describe partial anaerobiosis. Methane consumption will be included to describe consumption of methane, that is produced in the soil or that is withdrawn from the atmosphere. The methane production submodel is described in this paper.

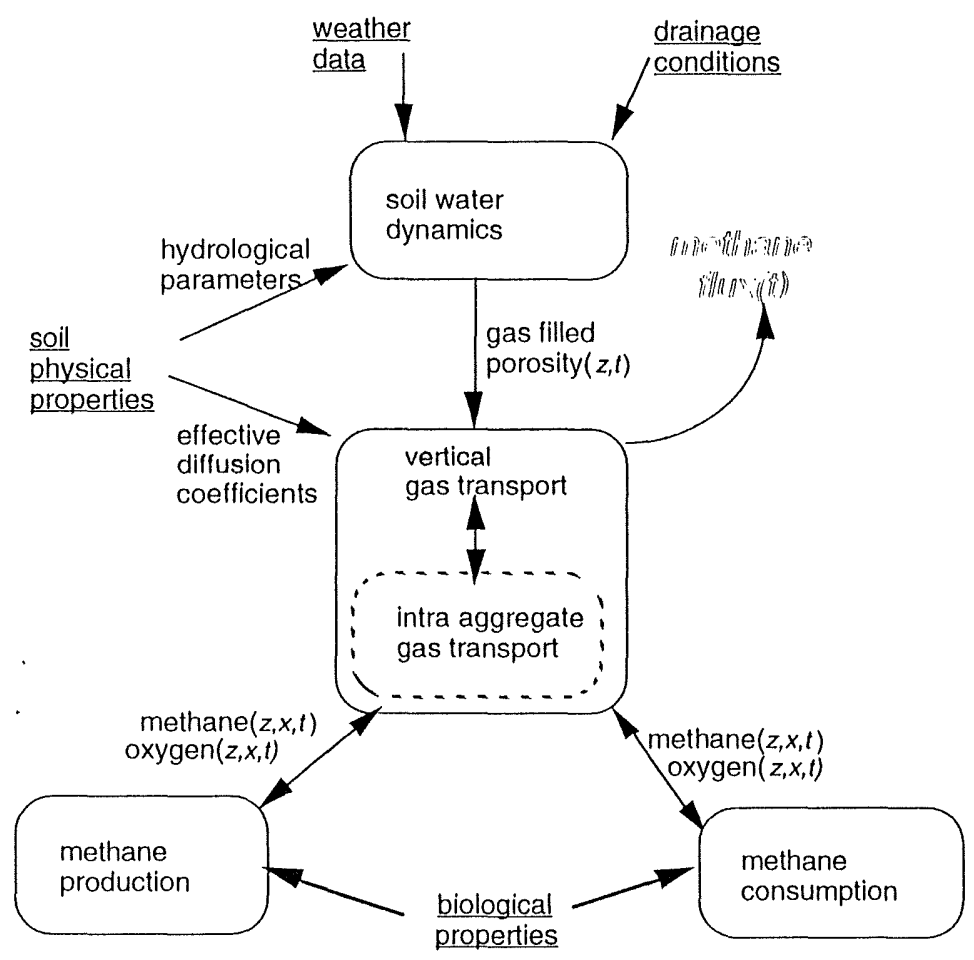

Figure 1. Sketch of the methane model for the drained site, Zegveld. $z$ denotes depth, $x$ the distance from the gas continuous phase, and $t$ the time. For clarity the influence of temperature is omitted. However, the influence of temperature $(z, t)$ on biological processes will be incorporated.

\section{METHANE PRODUCTION}

The methane production model is based on theoretical insights and experimental data of Kengen and Stams (pers. comm.). They collected soil samples from various depths, made slurries, and incubated these samples anaerobically at $15^{\circ} \mathrm{C}$. Experimental details are given in Kengen and Stams (1994). The quickest and highest methanogenic activity was observed in the samples from the $0-5 \mathrm{~cm}$ layer and, somewhat less, from the $5-10 \mathrm{~cm}$ layer. Deeper layers did 
hardly show any methane production. Therefore, experimental and modelling research has been focussed on samples from the top soil. In Figure 2 time series of methane, acetate, and carbon dioxide upon anaerobic incubation are given. After a lag phase of several days methane in the headspace of the flasks started to increase exponentially concurrent with the accumulation of acetate. After a few weeks the increase in methane concentration became rather constant. At about the same time acetate disappeared. So, three phases can be distinguished. In the first phase methanogenesis is not observable, because a) growth is below detection limit, b) methanogens are poisoned or outcompeted as a result of the presence of electron acceptors, or $\mathrm{c}$ ) the bacteria need time to adapt to changed conditions. In the second phase methanogenesis is limited by biomass and finally it is substrate limited. Generally it is assumed that most methane is formed from acetate or hydrogen and carbon dioxide (e.g. Conrad, 1989 or Cicerone and Oremland, 1988). Here, acetate seems to be the major substrate for the bacteria as no hydrogen accumulation was observed. This is supported by other experiments of Kengen and Stams (1994) with the same slurries
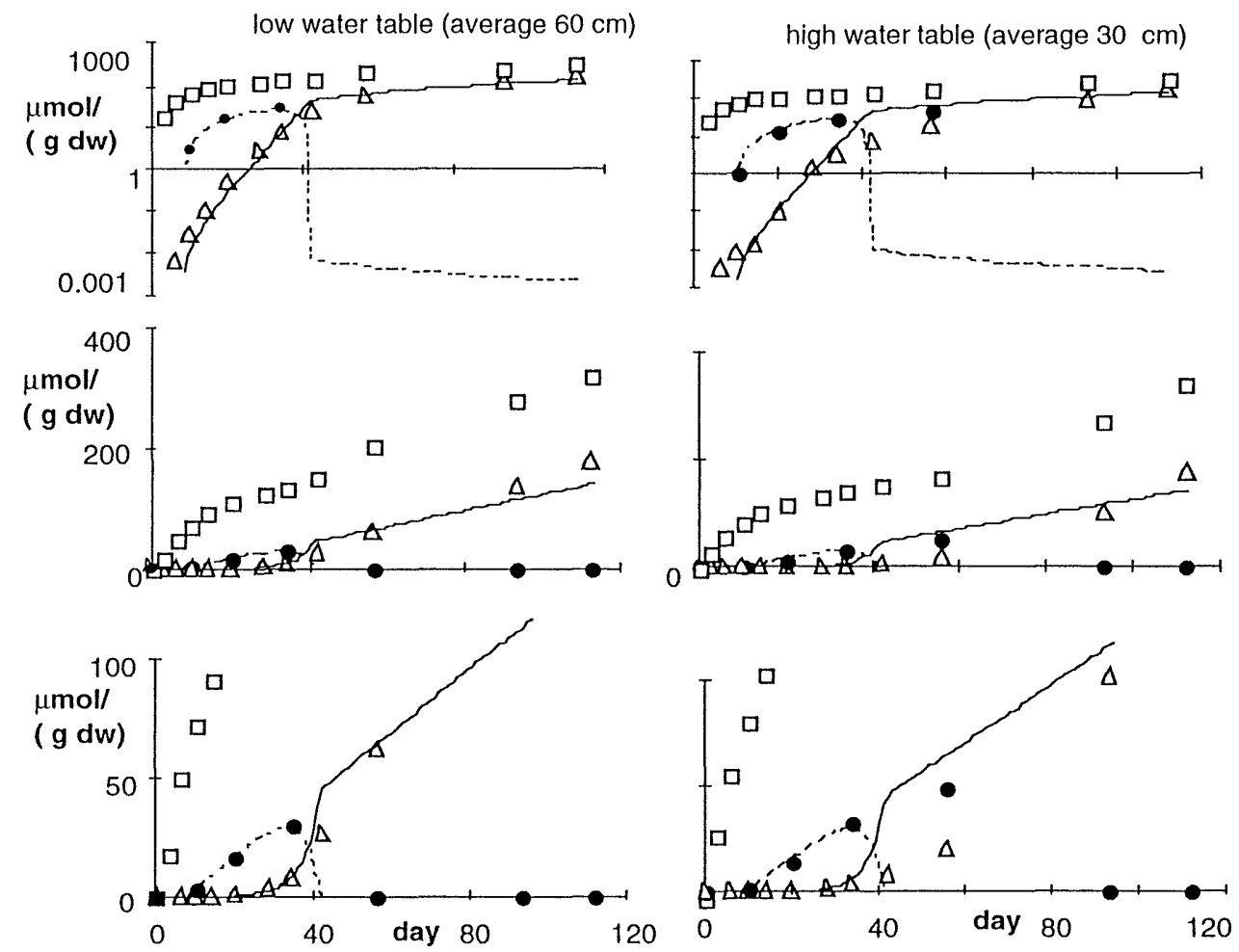

Figure 2. Measured and simulated time series of $\mathrm{CH}_{4}, \mathrm{Ac}$, and $\mathrm{CO}_{2}$ in anaerobically incubated soil samples from the 0-5 cm layer $\Delta=\mathrm{CH}_{4}$ (meas), $\bullet=\mathrm{Ac}$ (meas), $\mathrm{Q}=\mathrm{CO}_{2}$ (meas), $-=\mathrm{CH}_{4}(\mathrm{sim}$ ),

$\ldots . . . . .=A c(\operatorname{sim})$. The same data are plotted three times above each other. In the figures with the logaritmic axis zero concentrations could not be plotled. Measured values were assigned the value zero, when they were below the detection limit. Acetate was monitored less frequently than the other species. 
Because of the time dependence of the methane production, a dynamic model is appropriate. During anaerobic periods the methane production potential will grow, during aerobiosis it will decay. If $P$ represents production and $B$ the methanogenic biomass, the general concept of the methane production model can be described by equation (1) and (2):

$$
\begin{aligned}
& P=f_{\text {an }}(B, \alpha) ; \quad \quad \frac{\mathrm{d} B}{\mathrm{~d} t} \geq 0 \quad \text { anaerobiosis } \\
& P=0 ; \quad \frac{\mathrm{d} B}{\mathrm{~d} t} \leq 0 \quad \text { aerobiosis }
\end{aligned}
$$

In this set of equations $f_{a n}$ is a function to be determined. $\alpha$ represents a set of variables, influencing methanogenesis. Using the experimental data from Figure 2 the anaerobic part of the model (eq. 1) can be further developed (eq. 3-6). All three phases, which have been discussed earlier, are covered by the model.

$$
\begin{aligned}
& t<t_{\text {lag: }}: \quad P=0 \quad t>\text { tlag: } \quad P=\frac{\mu B}{Y}(1-Y) \frac{1}{\mathrm{~W}_{\mathrm{Ac}}} \\
& \frac{d B}{d t}=0 \\
& \frac{d A c}{d t}=0 \\
& \frac{d B}{d t}=\mu B \\
& V \frac{d A c}{d t}=Z-\frac{\mu B}{Y} \\
& \mu=\mu_{m} \frac{A c}{A c+K_{A c}}
\end{aligned}
$$

Here, $t$ represents the time and $t_{\text {lag }}$ the time during which methanogenesis does not occur yet. $\mu$ represents the relative growth rate of, acetate using, methanogenic biomass $B . Y$ is the yield of methanogenic biomass on acetate and $\mathrm{W}_{\mathrm{Ac}}$ is the molar weight of acetate. $A c$ is the concentration of acetate, $V$ is the volume of the water phase, $\mu_{m}$ is the maximum relative growth rate and $K_{A c}$ the Monod constant for acetate consumption. $Z$ is the acetate production, which is assumed to be constant after the lag time.

For $Y$ and $K_{A C}$ values from literature have been taken: $Y=0.04$ (g biomass/g acetate), Pavlostathis and Gomez (1991) and $K_{A C}=0.05\left(\mathrm{~g} / \mathrm{m}^{3}\right)$ (assuming $\mathrm{pH}=5$ and species

M. barkeri), Fukuzaki et al. (1990). These parameters were determined for possibly different methanogenic, acetate using, bacteria at, certainly, different temperatures than in our case. However, given the range of the other parameters, the model is not sensitive for these two parameters. So neglecting these differences does not seem too dangerous.

tlag and $Z$ have been determined by linear regression on the data for acetate, using only the points, where methane produced was still negligible compared to the acetate produced. This implies that it is assumed that acetate is consumed by methanogenic bacteria only. In the case of low water table two data points (on day 10 and 20) and in the case of the high water table three data points (on day 10,20 and 34) were available for this fit.

The maximum relative growth rate, $\mu_{m}$ and the initial amount of methanogenic biomass after the lag time, $B_{i}$, were determined from the data on methane in the headspace during exponential 
increase of methane in the headspace. Because it is rather arbitrary during which part of the experiment exponential growth occurred, two fits have been carried out for determining maximum relative growth rate and initial amount of methanogenic biomass, using a different number of data points. However, the results of the simulations did not differ much. Therefore, only the result of one simulation is given in Figure 2 .

\section{RESULTS AND DISCUSSION}

In Table 1 the fitted parameters for the model are presented. The depth dependence seems to be stronger than the site dependence.

Table 1.

Fitted parameters for the methane production model. "low" refers to the site with low water table. "high" refers to the site with high water table. 0-5 means slurries derived from soil samples taken from the $0-5 \mathrm{~cm}$ soil layer. -1 and -2 refer to the number of the fit.

\begin{tabular}{|c|c|c|c|c|}
\hline sample & $\mu_{m}(I / d)$ & $\operatorname{llag}(d)$ & $Z(\mu m o l /(g d w d)$ & $B_{i}(g$ bio $/ g d w$ soil $)$ \\
\hline low $(0-5)-1$ & 0.237 & 7.77 & 1.39 & $3.95 \mathrm{E}-08$ \\
\hline$(0-5)-2$ & 0.281 & 7.77 & 1.39 & $3.40 \mathrm{E}-08$ \\
\hline$(5-10)$ & 0.179 & 30.7 & 0.604 & $5.05 \mathrm{E}-09$ \\
\hline high $(0-5)-1$ & 0.277 & 9.23 & 1.31 & $1.60 \mathrm{E}-08$ \\
\hline$(0-5)-2$ & 0.264 & 9.23 & 1.31 & $1.66 \mathrm{E}-08$ \\
\hline$(5-10)-1$ & 0.259 & 29 & 0.401 & $2.54 \mathrm{E}-08$ \\
\hline$(5-10) \div 2$ & $0.192 \ldots$ & 29 & 0.401 & $3.82 \mathrm{E}-08$ \\
\hline
\end{tabular}

In Figure 2 the simulations with the fitted parameters are given for the two samples from the 0-5 $\mathrm{cm}$ layer. In the case of the low water table, the transition from the exponential to the linear phase is well described by the model. In the other case another limitation than substrate was probably present around day 40 , because acetate was still present, when the increase of methane in the headspace slowed down. It is surprising that in both cases the simulated final amount of methane (after 4 months) deviates only 30\% from the measured amount. So acetate production seems to have been quite constant after the lag time.

With sophisticated parameter estimation methods and more data points a better estimate of the parameters could be made. However, these simulations have only been used to get an insight in the order of magnitude of the processes involved. Before focussing on the exact values and variation of parameters the relative importance of the parameters in the overall model should be clear. Especially more knowledge about the processes during the lag time and during aerobiosis (eq. 2), and (an)aerobiosis dynamics should be obtained. The large $\mathrm{CO}_{2}$ production during the lag time should originate from some process, which needs electron acceptors. Therefore, the experiment will be repeated (by Kengen and Stams) with the monitoring of alternative electron 
acceptors, $\mathrm{NO}_{3}^{-}, \mathrm{SO}_{4}^{2-}$ and $\mathrm{Fe}^{3+}$. Possibly methanogenesis is poisoned or outcompeted by the presence of one or more of these electronacceptors during the lag time. To investigate the decay of the bacteria responsible for methane production during aerobiosis, experiments with changing oxygen conditions will be carried out. Insight in anaerobiosis dynamics will be gained with the gas transport model (driven by the water dynamics).

In summary, the methane production model was calibrated by the first part of the time series and validated by the second part. Together with cooperators from a related project we intend to further develop the model by understanding the black box parameter $t_{\text {lag }}$ and the decay of the methanogenic consortium during aerobiosis.

\section{Acknowledgements}

This project was partly financed by the Dutch National Research Programme on Global Air Pollution and Climate Change. The authors thank S.W.M. Kengen for providing the experimental data. The comments of S.W.M. Kengen, R. Rabbinge and the members of the PhD discussion group "Dynamies of water, nutrients and toxins in soils with different structures" of the C.T. de Wit Graduate School Production Ecology have been used to improve the paper.

\section{REFERENCES}

Cicerone, R.J. Oremland, R.S. (1988). Biogeochemical Aspects of Atmospheric Methane. Global Biogeochemical Cycles 2(4) p.299-327.

Conrad, R. (1989). Control of Methane Production in Terrestrial Ecosystems. Exchange of Trace Gases between Terrestrial Ecosystems and the Atmosphere p.39-58 Andrea (Ed.) M.O..

Dasselaar, A. van; Oenema, O. (this volume). Effects of Grassland Management on the Emission of Methane from Grassland on Peat Soils. Climate Change Research: Evaluation and Policy Implications - Proceedings of International Conference. Elsevier, Amsterdam, The Netherlands

Fukuzaki S.; Nishio, N.; Nagai, S. (1990). Kinctics of the Methanogenic Fermentation of Acetate. Applied and Envirommental Microbiology $\underline{56}$ p. 3158-3163.

Genuchten, M.Th. van (1980). A closed form equation for predicting the hydraulic conductivity of unsaturated soils. Soil Science Society Am. J. 44 p. 892-898.

Kengen, S.W.M. and Stams, A. F.J. M. (this volume). Methane formation by anaerobic consortia in grassland on peat soils.Climate Change Research: Evaluation and Policy Implications - Proceedings of International Conference. Elsevier, Amsterdam, The Netherlands

Pavlostathis,S.G.; Giraldo-Gomcz,E (1991). Kinctics of anacrobic treatment.. Water-Science-and-Technology. 24 (8) p. 35-59.

Segers, R. and Van Dasselaar, A. (this volume). The integrated $\mathrm{CH}_{4}$ grassland project: aims, coherence and site description. Climate Change Research: Evaluation and Policy Implications - Proceedings of International Conference. Elscvier, Amsterdam, The Netherlands

Wösten, J.H.M.; Veerman, G.J.; Stoltc, J. (1994). Waterretentic-en doorlatendheidskarakteristicken van bovenen ondergronden in Nederland: de Staringrecks. (in Dutch) Winand Staring Centre for Integrated Land, Soil and Water Rescarcb. RO Box 125,6700 AC Wageningen, The Netherlands. 